\title{
REGIONAL DIFFERENTIATION IN AGRICULTURAL DEVELOPMENT PATH ASSOCIATED WITH NATURAL AND SOCIAL ENVIRONMENTS: BASED ON 2000-2010 PROVINCIAL STATISTICAL DATA IN CHINA
}

\author{
Yoshio Kawamura ${ }^{1}$, Suxiang Bai ${ }^{2}$ \\ Kyoto Prefectural College of Agriculture and Ryukoku University, Japan. \\ Qufu Normal University, Shandong, China \\ Corresponding author e-mail: yoshiokawamura@ad.ryukoku.ac.jp
}

Citation: Kawamura, Y., Bai, S. 2020. Regional Differentiation in Agricultural Development Path Associated with Natural and Social Environments: Based on 2000-2010 Provincial Statistical Data in China. J. Asian Rur. Stud, 4(2): 230-240

\begin{abstract}
Agriculture is characterized by its organic manner of production. Thus, the forms of agricultural production are heavily dependent on natural conditions (weather, geographic features, water supply, etc.), which are peculiar to regions or local conditions. The regionally peculiar characteristics of agriculture are also intensified by the social environment, that is, the lifestyle of the people in the region. Land, labor and capital, which are the essential inputs needed for production, vary qualitatively and quantitatively from region to region. The regional peculiarities bring a different type of development path to local agriculture. This is the basic reason why the same development theory or principle cannot be applied to agriculture although it could be applicable in the case of other industries such as manufacturing. This paper deals with the characteristics of local agricultural development at the provincial level of China, based on statistical analyses of two sets of three-years data of 2009, 2010 and 2011 as well as 1999, 2000 and 2001. The analysis showed clear regional differentiation among the provinces between land-productivity oriented type and labor-productivity oriented type of agricultural development.
\end{abstract}

Keywords: Chinese Agriculture; Environments; Land-Productivity; Labor-Productivity; Regional Differentiation; Regional Peculiarity

\section{Introduction}

Agriculture owes its characteristics to the fact that it is an organic manner of production while other industries such as manufacturing are inorganic production. This means that the forms of agricultural production are heavily dependent on natural environments (meteorological and geographical, as well as water conditions, etc.), which are peculiar to regions or local conditions. At the same time, the regionally peculiar characteristics of agriculture are intensified by the social environment, that is, the lifestyle of local people in the region who are economic entities in agriculture. The essential inputs needed for agricultural production, land, labor and capital, are varied qualitatively and quantitatively from region to region. Land is directly affected by the natural environment and labor is also directly affected by the social environment. Even 
agricultural capital inputs are affected simultaneously by both the natural and social environment. Thus, the regional peculiarities bring different types of development path to regional agriculture. This is the basic reason why the same development theories or principles cannot be simply applied in agriculture, while such application could be done in the case of other industries such as manufacturing.

This means it is necessary to clarify the methods of evaluating regional agriculture and establishing its development framework based on the nature of regional characteristics determined by both natural and social environments. This is the purpose of this paper. For this, China was selected as research field because of the following two reasons. First, China has its exceptionally large territory with the vast range of natural and social diversity, indicating the high necessity to clarify such methods. This paper is to present China's agricultural structure based on regional characteristics determined by both natural and social environments. Second, despite of its huge scale with strong diversity, China is integrated as one country without boundary to normal economic activities, indicating ideal good research field to test relationships between normal economic activities and environments (external conditions). The data for the research was collected from the annual statistical data at the provincial level of 27 provinces, not including Beijing, Shanghai, Tianjin and Chongqing which are the major megalopolis regions in China. In the research, in order to avoid the error due to impacts of abnormality in weather change, the three-year average method was used. Thus the 2000 data was the three-year average of 1999, 2000 and 2001, while the 2010 data was the three-year average of 2009, 2010 and 2011.

\section{Theoretical Framework of Agricultural Development}

This session provides the basic framework of agricultural development associated with the natural and social environments. Although, in reality, different natural and social environmental conditions demonstrate complicated ab-modalities, these complexities are theoretically dichotomized and simplified into two extreme categories by introducing Max Weber's approach of dichotomization for ideal types. This is a powerful method to understand the characteristics of objectives by comparing the extremely opposite different cases. Figure 1 shows this dichotomization approach in the natural and social environments. "Temperate humid area" and "temperate dry area" are the categories of ideal types dichotomized based on natural environments, while "densely populated community" and "thinly populated community" are those dichotomized based on social environments.

Agriculture in "temperate humid area" is a regional form of agriculture conducted in the natural environment where the harvest per unit land will decrease if the land is left untouched during the period between seeding and harvesting, especially summer, without labor input such as weeding, since weeds grow rapidly in such hot-humid environments. In these regions, because the increase of labor input per unit land area in the thoroughness of crop growth management directly affects the harvest volume, agriculture necessarily becomes labor-intensive and agricultural growth depends on the improvement of land productivity. Therefore, capital intensification is directed toward the improvement of land productivity, and agriculture in such regions tends to develop into capital-intensive agriculture based on circulating (fluid) capital such as new species 
and fertilizers. Under the condition that labor power is limited, the agriculture will be restricted to relatively small-scale land management.

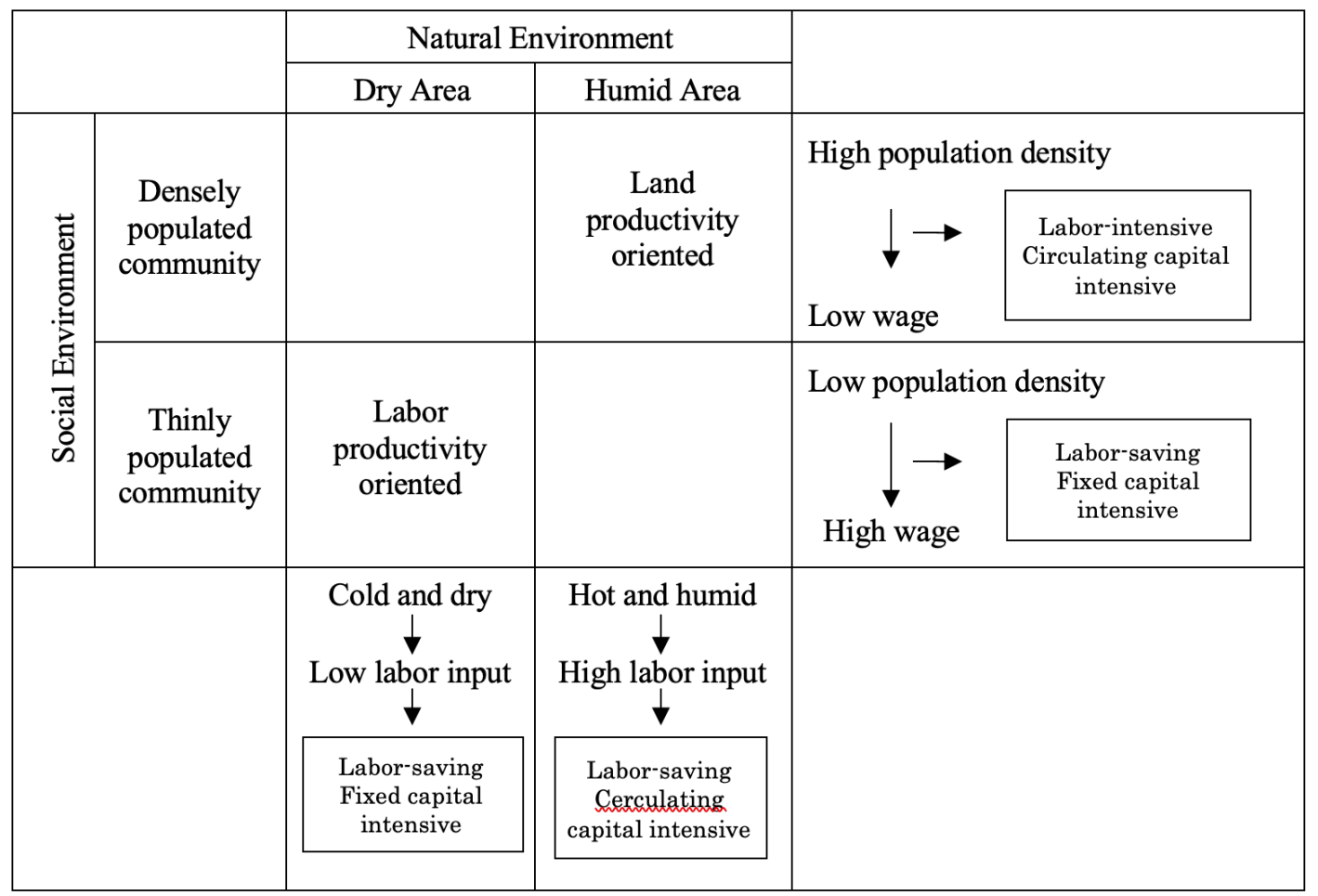

Figure 1: Agricultural Types in Temperate Regions

On the other hand, the agriculture in "temperate dry area" is a form of agriculture in a natural environment which is dry climate with relatively fewer weeds and thus has no clear correlation between the harvest per unit land and labor input per unit land during the period between seeding and harvesting. In these regions, since a greater area needs to cultivate by limited labor power within the short period between seeding and harvesting, the agriculture necessarily becomes labor-saving and thus agricultural growth depends on the improvement of labor productivity. Therefore, capital intensification is directed toward the improvement of labor productivity and thus the agriculture there tends to be capital-intensive agriculture based on fixed capital such as machinery. Thus, increase in the land management scale necessarily becomes the mechanism of agricultural growth.

"Densely populated community" in terms of the social environment refers to a community with high population density. This high population density causes an excessive labor supply, resulting in low wage levels. Thus, labor-intensive economic growth is a more rational approach in these communities. In terms of agriculture, since increase in the harvest can be achieved by increasing the labor input per unit land, the agriculture in such communities tends to be labor-intensive, and agricultural growth depends on the improvement of land productivity. Under the conditions of limited land availability with a great population, agriculture is restricted to relatively small-scale land management. 
On the other hand, "thinly populated community" refer to communities with low population density. This low population density causes a shortage of labor supply, resulting in high wage levels. Thus, labor-saving economic growth is a more rational approach in these communities. In terms of agriculture, since more land needs to cultivate with given condition of the limited labor force, the agriculture in such communities necessarily becomes labor-saving, and agricultural growth depends on the improvement of labor productivity. Thus, increase in the land management scale necessarily becomes the mechanism of agricultural growth.

In these agricultural categories, the unique form of regional agriculture determined by natural and social environments of "humid area" and "densely-populated community" stands in stark contrast to the unique form of regional agriculture determined by natural and social environments of "dry region" and "thinly-populated community," with regard to their growth mechanisms. The former regions tend to be directed towards labor-intensive agriculture, whose growth merkmal (feature) is the improvement of land productivity, whereas the latter regions tend to be directed toward labor-saving agriculture, whose growth merkmal is the improvement of labor productivity. Therefore, in terms of capital intensification, the intensification of circulating capital including the technological renovation of labor subjects generates progress in the former regions; on the other hand, the intensification of fixed capital including the technological renovation of labor generates progress in the latter regions. Hence, the key point is that agricultural growth mechanisms differ according to the natural and social environments.

\section{Result and Discussion}

\subsection{Provincial Distribution in the Natural and Social Environments}

The average annual temperature, temperature range, average annual humidity, humidity range, annual rainfall, and rainfall range were collected as important variables of the natural environments which directly affect the quality of land. Descriptive statistics analysis and correlation analysis of these six variables are shown in Table 1. This table reveals the following interesting results. Hunan Province (ID\#15 in Figure 2) had the highest, $24.3^{\circ} \mathrm{C}$, while Heilongjiang Province (ID\#6 in Figure 2) had the lowest average annual temperature of $5.0^{\circ} \mathrm{C}$. However, the correlation coefficient of the average annual temperature with the temperature range (the difference between the highest and lowest monthly temperature) shows $r=-0.78$, which is a negatively strong correlation. This means that a province with higher average annual temperature tends to be smaller gap in the annual temperature range, indicating relatively hot throughout the year. In contrast, a province with lower average annual temperature tends to be larger gap in the annual temperature range, indicating seasonally rough change in temperature, that is, hot summer and cold winter. A similar tendency can be seen with humidity. Hunan Province (ID\#15 in Figure 2) again had the highest of $81.0 \%$ and Tibet Autonomous Region (ID\#22 in Figure 2) had the lowest average humidity of $31.0 \%$. Once again, the correlation coefficient of the average annual humidity with its range ( $\mathrm{r}$ $=-0.63$ ) shows the tendency that a province with higher average annual humidity has smaller gap in the range meaning constantly muggy weather throughout the year, and a province with lower average in annual humidity tends to be bigger in the annual 
humidity range, which leads to substantial seasonal fluctuations in humidity. With regards to rainfall, which is directly related to humidity, Table 1 shows a positive strong correlation $(\mathrm{r}=0.83)$ indicating that a province with a large amount of annual rainfall experiences a large seasonal variability in rainfall, whereas a province with little annual rainfall experiences little seasonal rainfall variability, that is, dry throughout the year.

These six variables portraying the natural environments were run for the principal component analysis, extracting only one factor (principal component), as shown in farright side columns of Table 1 . This means that theses six variables are closely related each other enough to be unidimensional or one factor and thus, the scores of this principal component were converted into an index as a climate factor. The higher the climate index, the higher the temperature and humidity, the smaller the range (i.e., the difference between the maximum and minimum values), the higher the rainfall, and the larger the range of rainfall. In other words, if the climate index of a certain province is high, this means that its temperature and humidity are high, and it has a lot of rainfall. In addition, this tendency continues throughout the year.

Hainan (ID\#18 in Figure 2) and Fujian (ID\#10 in Figure 2) are typical provinces of high climate index. On the other hand, typical provinces with a low climate index are Heilongjiang (ID\#6 in Figure 2) and Xinjiang Uighur Autonomous Region (ID\#27 in Figure 2). Figure 2 is a scatter diagram of provinces between the climate index and the population density (log-transformed). It shows a significant positive correlation $(\mathrm{r}=$ 0.548) indicating that there exists a certain relationship between the natural environment and the population populated provinces are located only in the dry regions and, in the humid regions, only densely populated provinces are located. This fact seems to support partially the Ellsworth Huntington's classic hypothesis emphasizing the direct impact of natural conditions on social formation of people.

Table 1. Climate: Descriptive Statistics/Correlations and Principal Component

\begin{tabular}{|c|c|c|c|c|c|c|c|c|c|c|c|c|c|}
\hline & \multirow[b]{2}{*}{ Units } & \multirow[b]{2}{*}{ Freq. } & \multirow[b]{2}{*}{ Min. } & \multirow[b]{2}{*}{ Max. } & \multirow[b]{2}{*}{ Average } & \multirow[b]{2}{*}{ SD } & \multicolumn{5}{|c|}{ Correlation Coefficient } & \multicolumn{2}{|c|}{ Principal Component } \\
\hline & & & & & & & V1 & $\mathrm{V} 2$ & V3 & V4 & V5 & Component & Communality \\
\hline $\begin{array}{l}\text { V1. Average } \\
\text { annual } \\
\text { temperature }\end{array}$ & ${ }^{\circ} \mathrm{C}$ & 27 & 5.00 & 24.30 & 14.27 & 5.50 & 1 & & & & & 0.929 & 0.863 \\
\hline $\begin{array}{l}\text { V2. Temperature } \\
\text { range(differenc } \\
\text { e) }\end{array}$ & ${ }^{\circ} \mathrm{C}$ & 27 & 12.20 & 39.30 & 25.77 & 6.93 & $-0.78 * *$ & 1 & & & & -0.780 & 0.608 \\
\hline $\begin{array}{l}\text { V3. Average } \\
\text { annual } \\
\text { humidity }\end{array}$ & $\%$ & 27 & 31.00 & 81.00 & 63.62 & 11.26 & $0.64 * *$ & $-0.39 *$ & 1 & & & 0.764 & 0.584 \\
\hline $\begin{array}{l}\text { V4. Humidity } \\
\text { range } \\
\text { (difference) } \\
\end{array}$ & $\%$ & 27 & 10.00 & 42.00 & 26.48 & 9.46 & $-0.70^{* *}$ & $0.60 * *$ & $-0.63^{* *}$ & 1 & & -0.808 & 0.652 \\
\hline $\begin{array}{r}\text { V5.Annual } \\
\text { rainfall }\end{array}$ & $\mathrm{mm}$ & 27 & 180.00 & 2628.20 & 848.45 & 529.33 & $0.80^{* *}$ & $-0.56 * *$ & $0.71^{* *}$ & $-0.64 * *$ & 1 & 0.914 & 0.835 \\
\hline $\begin{array}{l}\text { V6. Rainfall } \\
\text { range } \\
\text { (difference) }\end{array}$ & $\mathrm{mm}$ & 27 & 64.60 & 560.60 & 202.29 & 120.68 & $0.70^{* *}$ & $-0.57 * *$ & $0.47^{*}$ & $-0.49 * *$ & $0.83^{* *}$ & 0.819 & 0.670 \\
\hline
\end{tabular}




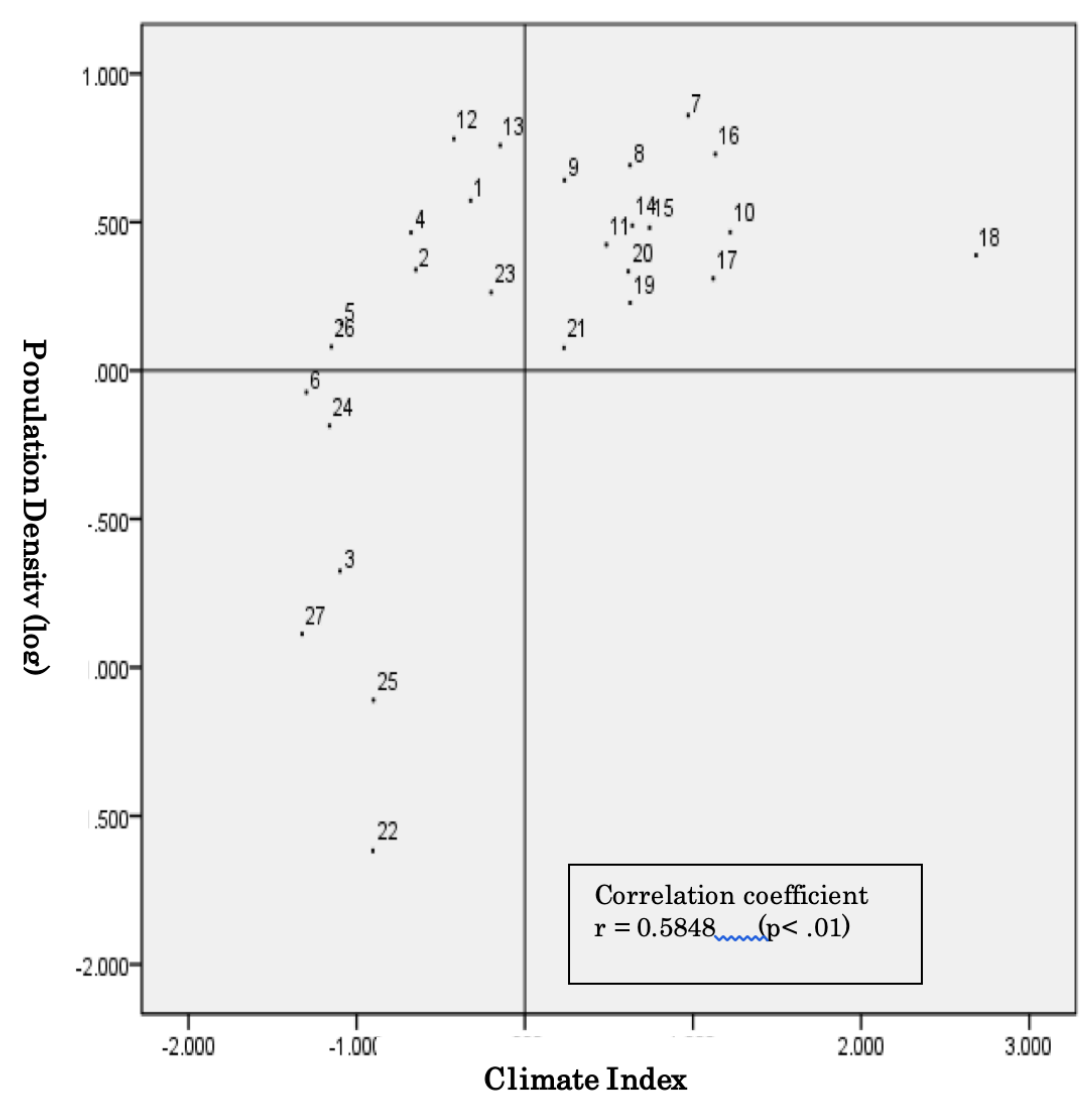

1. Hebei

2. Shanxi

3. Inner Mongolia Autonomous

Region

4. Liaoning

5. Jilin

6. Heilongiiang

7. Jiangsu

8. Zhejiang

9. Anhui

10. Fujian

11. Jiangxi

12. Shandong

13. Henan

14. Hubei

15. Hunan

16. Guangdong

17. Guangxi Zhuang

Autonomous Region

18. Hainan

19. Sichuan

20. Guizhou

21. Yunnan

22. Tibet Autonomous Region

23. Shaanxi

24. Gansu

25. Qinghai

26. Ningxia Hui Autonomous Region

27. Xinjiang Uighur Autonomous Region

Figure 2: Scatter Diagram of Provinces in Climate and Population Density (2010 China)

\subsection{Agricultural Development Path with Natural/Social Environments}

Figure 3 shows the changes in land productivity and labor productivity from 2000 to 2010 in the 27 provinces. In these 27 provinces, in 2000, the average land productivity was 3,940 yuan/ha, and the average labor productivity was 4,660 yuan/person; and in 2010 , the average land productivity was 16,880 yuan/ha, and the average labor productivity was 23,200 yuan/person. Therefore, the growth rates were 4.28 in land productivity and 4.98 in labor productivity, indicating slightly higher growth in labor productivity compared with land productivity. 


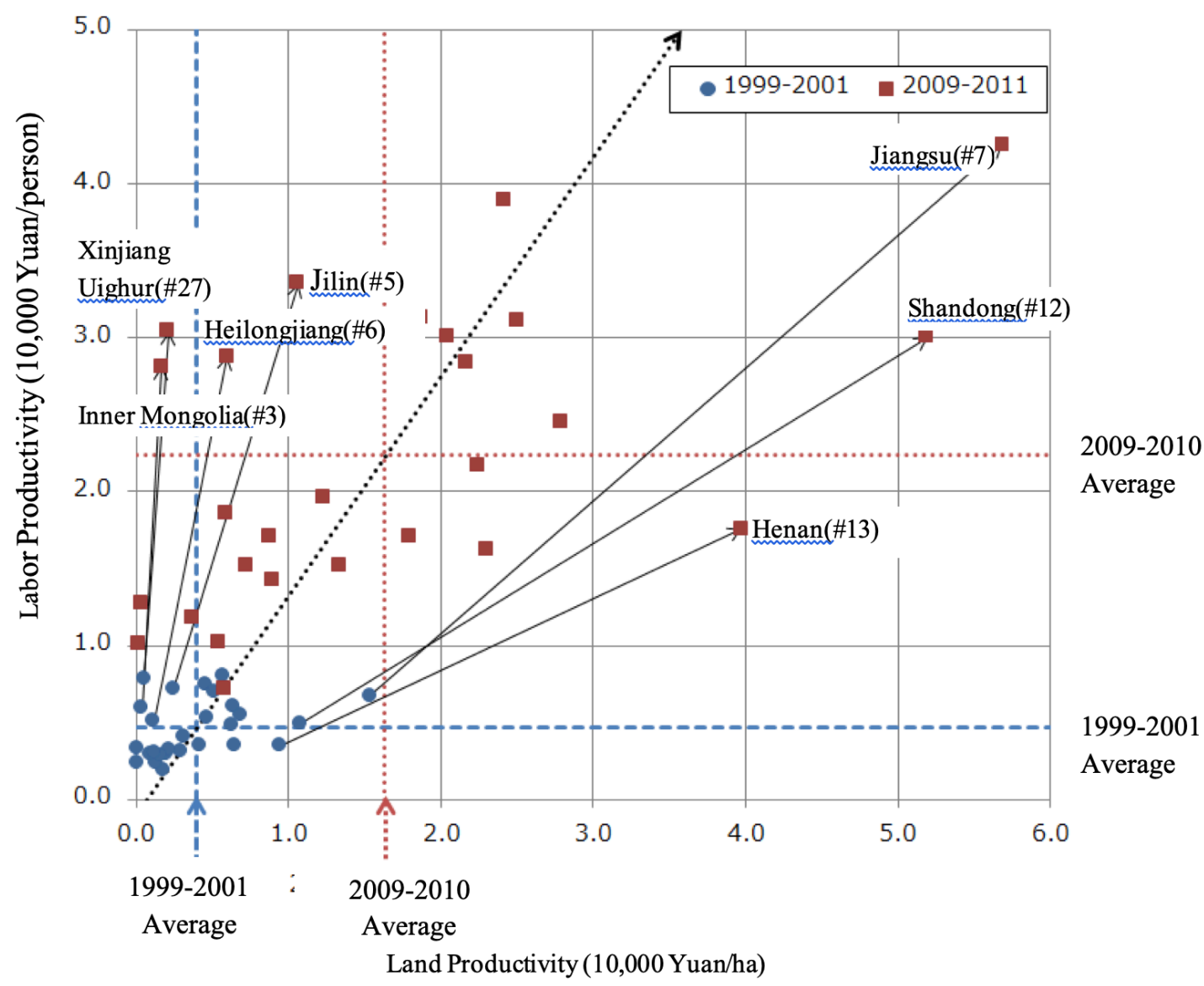

Figure 3: Scatter Diagram of Land Productivity and Labor Productivity (2000 - 2010)

The line in the figure, connecting the intersections of the average land productivity and the average labor productivity for 2000 and 2010, shows the agricultural progressive trend line of the overall China determined by both of these productivities. Similarly, a line connecting the average intersections for 2000 and 2010 of each province represents the agricultural progressive trend line of the province. If the provincial progressive trend line lies towards the $\mathrm{X}$-axis (land productivity axis) side from the overall agricultural progressive trend line, that is, a gentler slope than that of the overall agricultural progressive trend line, then that progressive trend shows more land-productivity oriented growth. In contrast, if the provincial agricultural progressive trend line lies towards the $\mathrm{Y}$-axis (labor productivity axis) side from the overall agricultural progressive trend line, that is, a steeper slope than that of the overall agricultural progressive trend line shows more labor-productivity-oriented agricultural growth. 
Figure 3 shows that Jiangsu (ID\#7 in Figure 2), Shandong (ID\#12 in Figure 2), and Henan (ID\#13 in Figure 2) are typical provinces that have sought land-productivity oriented agricultural growth. In Jiangsu, in 2000, land productivity was 15,300 yuan/ha and labor productivity was 6,790 yuan/person; in 2010, land productivity was 58,090 yuan/ha and labor productivity was 43,390 yuan/person. The growth of land productivity was 3,80 whereas the growth of labor productivity was 6.39 . In the case of Shandong, land productivity and labor productivity in 2000 were 10,780 yuan/ha and 5,010 yuan/person; , respectively. Those productivities increased to 52,840 yuan/ha and 43,390 yuan/person respectively indicating growth rates by 4.90 times and 8.66 times. Similarly, Henan had land productivity of 9,380 yuan/ha and labor productivity of 3,520 yuan/person in 2000 and in 2010 the former productivity grew to 41,460 yuan/ha and the latter became 18,350 yuan/person indicating the growth rate 4.42 times and 5.21 times respectively. Although these provinces share the general trend that the growth rate of labor-productivity has been slightly higher than that of land-productivity, their agriculture are strongly characterized with much higher land-productivity than the average (overall trend). Compared with the overall average in 2000, Jiangsu's land and labor productivity were respectively 3.88 and 1.46 times; Shandong's land and labor productivity were 2.74 and 1.08 times; and Henan's land and labor productivity were 2.38 and 0.76 times (that is, lower than the average). In the case of 2010 , Jiangsu's land and labor productivity were respectively 3.44 and 1.87 times of the average; Shandong's land and labor productivity were 3.12 and 1.31 times; and Henan's land and labor productivity were 2.46 and 0.79 times higher than the average.

Figure 3 also shows that there are provinces that obviously deviate from the general growth trend of Chinese agriculture in contrast to the above three provinces. Their progressive trend lines have almost vertical slopes, indicating strong labor-productivity oriented agricultural growth pattern. The figure shows that at least four provinces, namely Jilin (ID\#5 in Figure 2), Heilongjiang (ID\#6 in Figure 2), Inner Mongolia Autonomous Region (ID\#3 in Figure 2) and Xinjiang Uighur Autonomous Region (ID\#27 in Figure 2) are seen to have developed an agricultural growth pattern that is clearly labor-productivity oriented. In 2000, Jilin's land productivity was 2,380 yuan/ha and its labor productivity was 7,200 yuan/person which were 0.60 times lower and 1.55 times higher than the overall average respectively; in 2010, its land and labor productivities were 10,570 yuan/ha and 33,490 yuan/person respectively which became 0.63 times lower and 1.44 times higher than the overall average. The growth of land productivity was 4.44 times whereas the growth of labor productivity was 4.65 times. In the case of Heilongjian, land productivity and labor productivities in 2000 were 1,110 yuan/ha and 5,120 yuan/person, respectively, which were only 0.28 times lower and 1.10 times higher compared with the overall average. Those productivities in 2010 grew to 6,070 yuan/ha and 29,640 yuan/person which were still 0.36 times lower and 1.29 times higher than the overall average. These productivities indicate the growth rates by 5.47 times and 5.79 times respectively. Inner Mongolia, in 2000, had land productivity of only 350 yuan/ha, which was only 0.09 times $(9 \%)$ of the average, and labor productivity of 6,010 yuan/person which was 1.29 times higher than the average; in 2010 , the land productivity grew to 1,730 yuan/ha and the labor productivity became 29,310 yuan/person which were 0.10 times (only 10\%) and 1.26 times higher than the average. These figures indicate the growth rate 4.94 times and 4.88 times respectively. 
Similarly, Xinliang Uigur had land productivity of only 490 yuan/ha and labor productivity of 7,900 yuan/person in 2000 which were only 0.12 times less (that is, $12 \%$ ) and 1.70 times higher than the average; in 2010, the land productivity grew to 2,280 yuan/ha and the labor productivity became 33,710 yuan/person. Compared with the overall average, its land productivity was 0.14 times less (only 14\%) and the labor productivity was 1.45 times higher. These figures indicate the growth rate 4.65 times and 4.27 times respectively. These provinces are strongly characterized by very low land-productivity and thus their growth rates of land-productivity show even higher than changes in labor-productivity which are different feature from the general trend of the overall average.

\section{Conclusion}

The final integration of research was provided by Figure 4 . The figure shows the scatter diagram of the 27 provinces according to different types of agricultural progressive trend, based on Figure 2 showing the provincial distribution between the climate index and the population density. The provinces are categorized into three groups according to agricultural progressive trend line. The first group of provinces (shown by square marks in the figure) has clear land-productivity orientation in agricultural development whose progressive trend line is a gentler slope than that of the overall agricultural progressive trend line which is lying towards the X-axis (land productivity axis) side from the overall progressive trend line. The second group (shown by triangle marks in the figure) has an average situation lying around the overall agricultural progressive trend line. The third one (shown by circle marks in the figure) has clear labor-productivity orientation in agricultural development whose progressive trend line is a steeper slope than that of the overall progressive trend line, which is lying towards the $\mathrm{Y}$-axis (labor productivity axis) side from the overall progressive trend line. The first group has eight provinces including Jiangsu, Shandong and Henan. The second group has eleven provinces while the third group has eight provinces including Jilin, Heilongjiang, Inner Mongolia and Xinjiang Uighur.

Interesting fact findings in this figure are, first, that all of the provinces having the labor-productivity orientation in agricultural development path belong to the category determined by the natural environment of "dry region" which has a strong relationship with "thinly-populated community" and, second, that all of the provinces having the land-productivity orientation in agricultural development path belong to the category determined by the social environment of "densely-populated community" which has a tendency to be located in the natural environment of " humid region." 


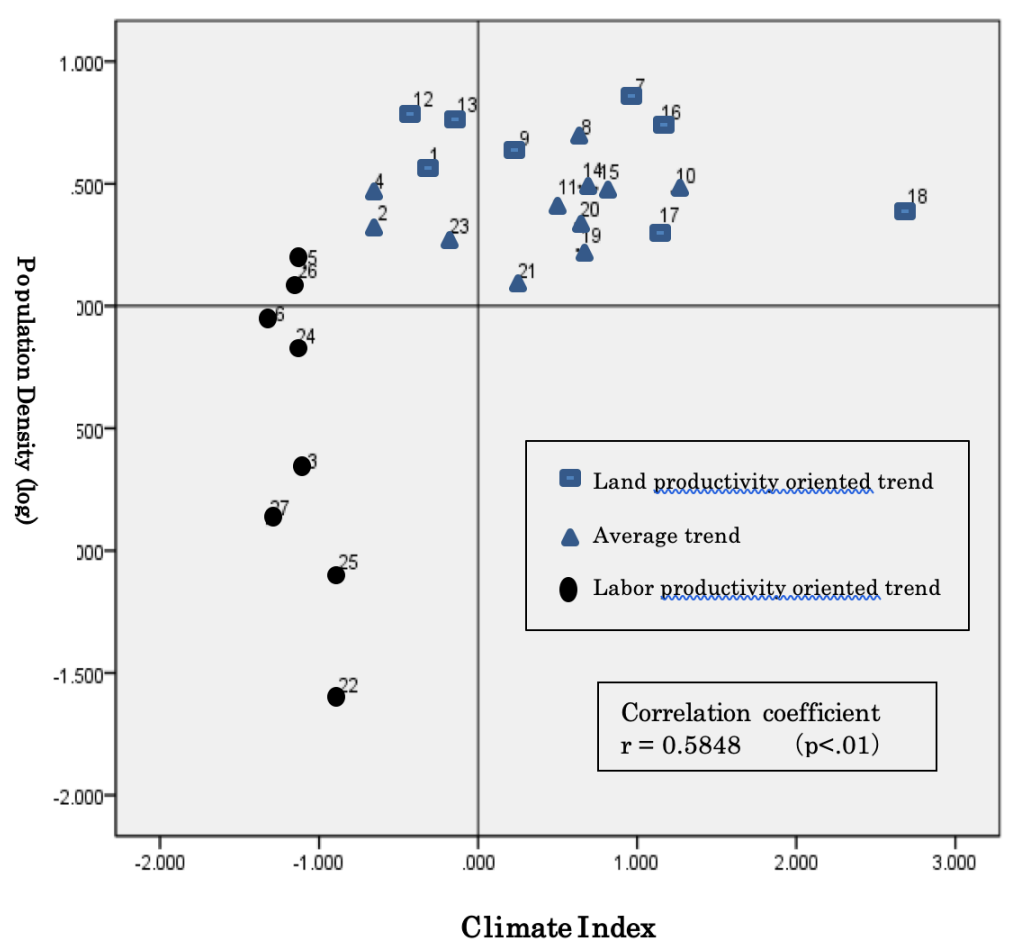

1. Hebei
2. Shanxi
3. Inner Mongolia Autonomous
Region
4. Liaoning
5. Jilin
6. Heilongjiang
7. Jiangsu
8. Zhejiang
9. Anhui
10. Fujian
11. Jiangxi
12. Shandong
13. Henan
14. Hubei
15. Hunan
16. Guangdong
17. Guangxi Zhuang
Autonomous Region
18. Hainan
19. Sichuan
20. Guizhou
21. Yunnan
22. Tibet Autonomous Region
23. Shaanxi
24. Gansu
25. Qinghai
26. Ningxia Hui Autonomous
Region
27. Xinjiang Uighur Autonomous
$\quad$ Region

Figure 4. Scatter Diagram of Provinces with Productivity Orientation

These fact findings are clearly indicating how strongly the natural and social environments at the regional/local level affect the differentiation in development path of agriculture, which is forming the peculiarity of agriculture. This differentiation is almost directly associated with dichotomized orientation between land-productivity and laborproductivity, which requires different capital inputs related to technology. Theoretically speaking, the land-productivity requires technology based on circulating capital inputs such as seed, fertilizer, and chemicals, while the labor-productivity requires technology based on fixed capital inputs such as machine and facility. This means the natural and social environments affect not only land and labor inputs but also capital inputs or technology. Because of such comprehensive impacts of the natural and social environments at the regional level, it is crucial for scientists and policy-planners to clarify the relationship between the agricultural development path and the natural and social environments at the regional level.

\section{References}

Hayami, Yujiro. 1988. Japanese agriculture under siege : the political economy of agricultural policies. Macmillan, New York

Huntington, Ellsworth. 1959. Mainsprings of Civilization. John Wiley and Sons, New York. 
Iinuma, Jiro. 1967. Nogyo Kakumei Ron [Agricultural Revolution]. Miraisya, Tokyo Imamura, Naomi. 1996. Dai 6-ji Sangyo no Sozo wo [To Create a Sixthiary Sector]. Gekkan Chiiki Zukuri [Monthly Journal-Regional Construction] 89, Chiiki Kasseika Senta, Tokyo

Kawamura, Yoshio. 1987. Noson Syakai no Henbo to Kasseika Seisaku no Arikata [Changes of Rural Societies and the Concept of a Revitalization Policy]. Nogyo to Keizai [Agriculture and Economy] (Special Edition: Agricultural Policy Council Report and New Development of Agricultural Policy): 66-75.

Kawamura, Yoshio. 2010. Grobaru Jidai ni okeru Kankyo/Shigen to Nogyo Kaihatsu: Fodizum to Nicchizum [Environment, Resources and Agricultural Development in a Global Age: Fordism and Nichism] In Hunso Kaiketsu Gurobaruka/Chiiki/Bunka [Conflict Resolution, Globalization, Region and Culture]. Eds., Pauline Kent, Atsushi Kitahara. Kyoto: Mineruva Syobo. pp.22-40.

Kawamura, Yoshio. 2014. Development Path Analysis of Chinese Agriculture with Land and Labor Productivity. Ed. K. Ikegami, From Challenges to a Prosperous Future in Rural Asia (Asian Rural Sociology V) Asian Rural Sociology Association, pp.208-218.

Kawamura, Yoshio. 2017. Alternative Development from Fordism to Nichism for Asian Agriculture in Globalizing Era. Journal of Asian Sural Studies 1(1): 1-12.

Kawamura, Yoshio., Hoshino, Satoshi., Mese, Morio. 1994. Chiiki Kasseika to Keikaku [Regional Revitalization and Planning]. Meibun Shobo, Tokyo

Koike, Tsuneo. ed. 1998. Chiiki Nogyo no Hatten to Chiho Jichitai [Development of Regional Agriculture and Local Government]. Ie-no-Hikari Kyokai. Tokyo

Mese, Morio., Yoshimitsu Torigoe, Yoshio Kawamura, Toyonobu Sato, Toyokazu Yano. 1991. Kuristaru Roman Ohotsuku [Crystal Roman Okhotsku]. Meibun Shobo. Tokyo

Sakamoto, Keiichi., Toshihiro Takayama. eds. 1983. Chiiki Nogyo no Kakushin [Renovation of Regional Agriculture]. Meibun Shobo, Tokyo

Tomczak, Franciszek, (2001). From Peasant Agriculture to Agribusiness: Path of the Family Farms (Households) Development, Annual Bulletin of Research Institute for Social Sciences, No.30, Ryukoku University.

Weber, Max (translated by H. P. Secher). 1962. Basic Concepts in Sociology. The Citadel Press, New York.

Yori, Taira (ed). 1992. Kokusai-ka Jidai no Nogyo Keizaigaku [Agricultural Economics in a Globalizing Era]. Fumin Kyokai, OsakaEcol Food Nutr, 45: 87-103. 